Original Research Article

\title{
Study on knowledge, attitude and practices with respect to antibiotic use among medical students
}

\author{
D. Bhavika*, A. Naga Teja Pavani, G. Meghavani, Aditya Jillella, Sameer Uz Zaman
}

Department of Pharmacology, Kamineni Academy of Medical Sciences and Research Centre, Hyderabad, Telangana, India

Received: 03 May 2019

Accepted: 31 May 2019

*Correspondence to:

Dr. D. Bhavika,

Email: bhavika_mb6

@yahoo.co.in

Copyright: (C) the author(s), publisher and licensee Medip Academy. This is an openaccess article distributed under the terms of the Creative Commons Attribution NonCommercial License, which permits unrestricted noncommercial use, distribution, and reproduction in any medium, provided the original work is properly cited.

\begin{abstract}
Background: Antibiotic resistance has emerged as a serious global problem. Irrational prescribing of antibiotics is one of the key factors responsible for the development of antibiotic resistance. As today's medical students will be the future prescribers their awareness regarding antibiotic resistance and rational prescribing of antibiotics is very much important. The main objective of the study was to evaluate the knowledge, attitude and practices of the medical students towards antibiotic use.

Methods: A cross-sectional questionnaire-based study was conducted involving the medical students from all the semesters. A predesigned questionnaire was used to evaluate the knowledge, attitude and practices of the respondents. The response options were 'yes' or 'no' for some questions, and a 5 point Likert scale used to assess some questions. The data was analyzed using MS office Excel.

Results: A total of 457 fully completed questionnaires from the respondents were evaluated. Majority of the respondents $(70 \%)$ were females, and $91 \%$ of the respondents were aware of antibiotic resistance as a global problem. On analysis of score of questions assessing knowledge, $91 \%$ of respondents had attained a score in the range of 5-7. Majority (83\%) of the respondents used antibiotics only on doctor's prescription and $74 \%$ of the respondents had completed the prescribed course.

Conclusions: The present study gives an insight on the knowledge, attitude and practices of medical students on antibiotic use, and can be used as a tool to plan educational strategies to improve the knowledge of the students regarding rational use of antibiotics.
\end{abstract}

Keywords: Antibiotic use, Antibiotic resistance, Attitude, Knowledge, Medical students

\section{INTRODUCTION}

Resistance to antimicrobial agents is a major public health issue. With the development of new resistance mechanisms, treatment of common infectious diseases has become difficult, leading to an increase in morbidity and even mortality. The key factor leading to increasing rates of antimicrobial resistance is the overuse and misuse of antimicrobial agents in humans as well as in animals.
Antibiotics since long have been protecting humanity from various infectious diseases. Lately, there has been rapid emergence of resistance due to overuse, inappropriate use (due to incorrect choice of agent, treatment indication and duration of treatment) and unprohibited/irrational use of antimicrobial agents in livestock to promote growth and prevent infections. ${ }^{1}$ 
As today's medical students will be future clinicians prescribing antimicrobial agents, their knowledge, attitude and practices with respect to the usage of antimicrobial agents and their perception towards the issue of rapidly emerging antimicrobial resistance is of utmost importance. Studies were conducted evaluating the knowledge, attitude and practices of medical students towards antimicrobial use in many countries and addressed the need to educate medical students about the rational use of antimicrobial agents and to introduce an antibiotic stewardship program into undergraduate medical education. ${ }^{2,3}$ This study aims to assess the knowledge, attitude and practices of medical students regarding the usage of antibiotics and their perception towards the crisis of antibiotic resistance.

\section{METHODS}

\section{Study design}

A cross sectional questionnaire-based study was conducted during the period of March-April 2019, to evaluate the knowledge, attitude and practices of medical students studying at Kamineni Academy of Medical Sciences and Research Centre, Hyderabad, India regarding the usage of antibiotics.

\section{Study population}

Medical students of all the semesters, studying in Kamineni Academy of Medical Sciences and Research Centre, Hyderabad, India and willing to participate were included in the study.

\section{Data collection}

Data was collected from medical students according to a predesigned questionnaire prepared to meet the requirements of the study and covering basic sections like knowledge, attitude and practices. The questionnaire was prepared, based on review of literature from similar studies $^{2-6}$ The first part of the questionnaire comprised of demographic details like age, gender, and some general questions like any known person in the field of health care. The second part included questions assessing the participant's knowledge, attitude and practices related to antibiotic use and antibiotic resistance. For the questions assessing knowledge the response options were 'Yes' or 'No'. A 5-point Likert scale ranging from 'strongly agree' to 'strongly disagree' and 'always' to 'never' was used to assess the attitude and practices respectively.

\section{Data analysis}

Data was analyzed using simple descriptive statistics with the help of MS Excel and results were expressed in terms of percentages and proportions. A knowledge related score was generated ranging from 0-7 for the knowledge related questions and the score was compared between the students of all the years of medical college study.

\section{RESULTS}

A total of 496 students participated in the study, but the questionnaires from 457 students who had responded to the important questions of the basic constructs of knowledge, attitude and practice were analyzed, while 39 (8\%) questionnaires were omitted from the study, as key questions were not answered. Among the 457 respondents, majority were females $(70 \%)$. The ages of the respondents were in the range of 17 years to 23 years (mean age being $20 \pm 1.3$ ) (Table 1). The age distribution of the respondents is presented in (Table 2). The number of respondents from each year of MBBS course are shown in (Table 1). $66 \%$ of the respondents had a known person in the field of health care, and among the respondents majority had relatives $(49 \%)$ in the healthcare field, followed by sibling $(5 \%)$, father $(4 \%)$ and mother $(1 \%)$ (Table 1$)$.

Table 1: Demographic and general characteristics of the respondents $(n=457)$.

\begin{tabular}{|c|c|c|}
\hline $\begin{array}{l}\text { Demographic } \\
\text { characteristics }\end{array}$ & & n $(\%)$ \\
\hline \multirow{2}{*}{ Gender } & Male & $135(30 \%)$ \\
\hline & Female & $322(70 \%)$ \\
\hline Mean age (in years) & $20( \pm 1.3)^{*}$ & \\
\hline \multirow{4}{*}{ Year of study } & First year & $110(24 \%)$ \\
\hline & Second year & $108(24 \%)$ \\
\hline & Third year & $127(28 \%)$ \\
\hline & Fourth year & $112(25 \%)$ \\
\hline \multirow{2}{*}{$\begin{array}{l}\text { Known person in } \\
\text { field of health care }\end{array}$} & Yes & $301(66 \%)$ \\
\hline & No & $156(34 \%)$ \\
\hline \multirow{5}{*}{$\begin{array}{l}\text { Relation with the } \\
\text { known person in the } \\
\text { field of health care }\end{array}$} & Mother & $6(1 \%)$ \\
\hline & Father & $20(4 \%)$ \\
\hline & Sibling & $24(5 \%)$ \\
\hline & Relatives & $222(49 \%)$ \\
\hline & $\begin{array}{l}\text { Two or more } \\
\text { known } \\
\text { persons }\end{array}$ & $29(6 \%)$ \\
\hline
\end{tabular}

*Mean ( \pm Standard deviation)

Table 2: Age distribution of the respondents $(n=457)$.

\begin{tabular}{|llll|}
\hline Age group (in years) & Male & Female & Total \\
\hline $17-19$ & 41 & 143 & 184 \\
\hline $20-23$ & 94 & 179 & 273 \\
\hline Total & 135 & 322 & 457 \\
\hline
\end{tabular}

On analysis of knowledge related questions (Table 3), majority of the respondents were aware of antibiotic resistance $(97 \%)$, and the problem of antibiotic resistance globally $(91 \%)$ and in India (89\%). $83 \%$ of respondents were aware that antibiotics cannot be used in treatment of viral infections, and $72 \%$ were aware that use of antibiotics does not speed up recovery from cold and cough. Majority of the respondents $(96 \%)$ were aware that frequent and irrational use of antibiotics will render them ineffective on future use. 
Table 3: Questions evaluating the knowledge of respondents.

\begin{tabular}{|lll|}
\hline Questions evaluating Knowledge & Yes (\%) & No (\%) \\
\hline Can antibiotics be used for treatment of viral infections & $76(17 \%)$ & $38(83 \%)$ \\
\hline Do you think use of antibiotics can speed up recovery of cold, cough? & $126(28 \%)$ & $331(72 \%)$ \\
\hline Did you hear about antibiotic resistance? & $443(97 \%)$ & $14(3 \%)$ \\
\hline Do you think antibiotic resistance is a serious global problem & $417(91 \%)$ & $40(9 \%)$ \\
\hline Do you think antibiotic resistance is a serious problem in India & $406(89 \%)$ & $51(11 \%)$ \\
\hline Frequent and irrational use of antibiotics will render them ineffective on future use & $441(96 \%)$ & $16(4 \%)$ \\
\hline Antibiotics can be obtained at the pharmacies without a valid prescription & $162(35 \%)$ & $295(65 \%)$ \\
\hline
\end{tabular}

On analysis of the score of the knowledge related questions, it was observed that $91 \%$ of the respondents had knowledge scores of 5-7 and 9\% with a score in range of 2-4 (Table 4). The score represents the number of correct responses out of the 7 questions included in the knowledge assessing section of the questionnaire. The attitude of the respondents towards the use of antibiotics is presented in (Table 5). On analysis of the practices of the respondents, $35 \%$ of the respondents had purchased antibiotics without a prescription, and $74 \%$ of the respondents had completed the course of antibiotics prescribed (Table 6).
Table 4: The score of the responses to questions evaluating knowledge.

\begin{tabular}{|llllll|}
\hline Score & $\begin{array}{l}\text { Percentage of respondents } \\
\text { First } \\
\text { year }\end{array}$ & $\begin{array}{l}\text { Second } \\
\text { year }\end{array}$ & $\begin{array}{l}\text { Third } \\
\text { year }\end{array}$ & $\begin{array}{l}\text { fourth } \\
\text { year }\end{array}$ & Total \\
\hline $0-1$ & 0 & 1 & 0 & 0 & $<1 \%$ \\
\hline $2-4$ & 15 & 14 & 4 & 3 & $9 \%$ \\
\hline $5-7$ & 85 & 85 & 96 & 97 & $91 \%$ \\
\hline
\end{tabular}

Table 5: Statements assessing the attitude of the respondents towards antibiotic use.

\begin{tabular}{|c|c|c|c|c|c|}
\hline \multirow{2}{*}{ Statements assessing attitude } & \multicolumn{5}{|c|}{ Percentage of respondents } \\
\hline & SA & $\mathbf{A}$ & $\mathbf{U}$ & D & SD \\
\hline Taking antibiotics for fever, cough, cold will resolve the symptoms faster & 2 & 39 & 24 & 27 & 8 \\
\hline You should stop using antibiotics once the symptoms are relieved & 13 & 20 & 8 & 30 & 29 \\
\hline Using newer antibiotics will effectively treat bacterial infections & 13 & 50 & 29 & 7 & 1 \\
\hline
\end{tabular}

Response: SA-Strongly agree, A-Agree, U-Undecided, D-Disagree, SD-Strongly Disagree

Table 6: Practices of the respondents regarding antibiotic use.

\begin{tabular}{|llll|}
\hline Practice related questions (\% of respondents) & Yes & No & Don't remember/Uncertain \\
\hline Purchased antibiotics without prescription & 35 & 55 & 10 \\
\hline Asked doctor to prescribe antibiotic when not prescribed & 8 & 86 & 6 \\
\hline Completed the prescribed course & 74 & 16 & 10 \\
\hline
\end{tabular}

Table 7: Practices of the respondents regarding antibiotic use.

\begin{tabular}{|c|c|c|c|c|c|}
\hline \multirow{2}{*}{ Use of antibiotics in- } & \multicolumn{5}{|c|}{ Respondents (\%) } \\
\hline & Always & Often & Sometimes & Rarely & Never \\
\hline Common cold & 2 & 6 & 21 & 26 & 45 \\
\hline Cough & 2 & 8 & 24 & 27 & 39 \\
\hline Diarrhoea & 7 & 14 & 28 & 20 & 31 \\
\hline Sore throat & 10 & 18 & 32 & 18 & 21 \\
\hline
\end{tabular}

On evaluation of the practices of antibiotic use in different conditions, it was observed that $26 \%$ of the respondents had rarely used and $45 \%$ of the respondents had never used an antibiotic for common cold. Antibiotic usage pattern in conditions like cough, diarrhoea, sore throat was also assessed (Table 7). On evaluation of practices regarding the source of antibiotic (Figure 1), majority (83\%) have the 
habit of procuring antibiotics following a doctor's prescription.

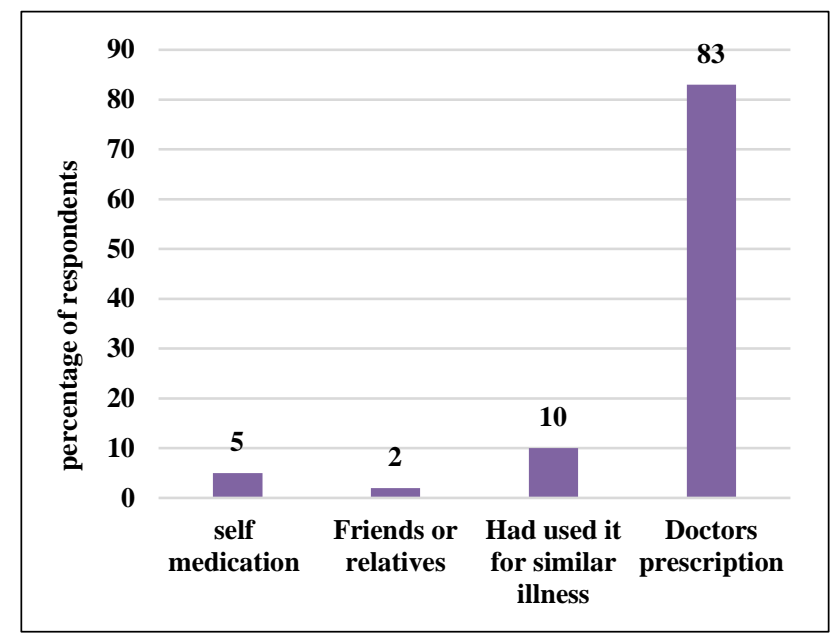

Figure 1: Source of antibiotics procured by respondents.

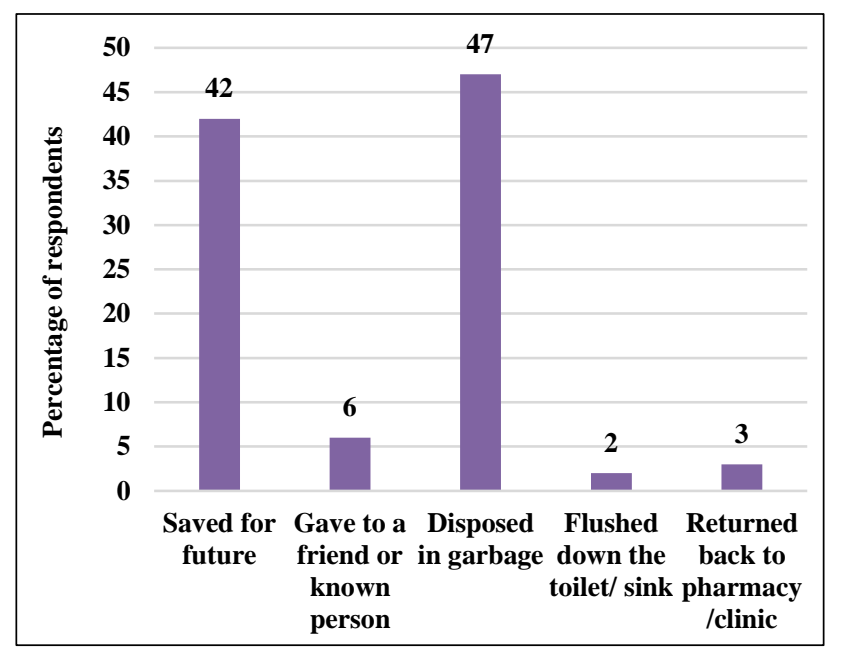

Figure 2: Methods of disposal of antibiotics by the respondents $(n=173)$.

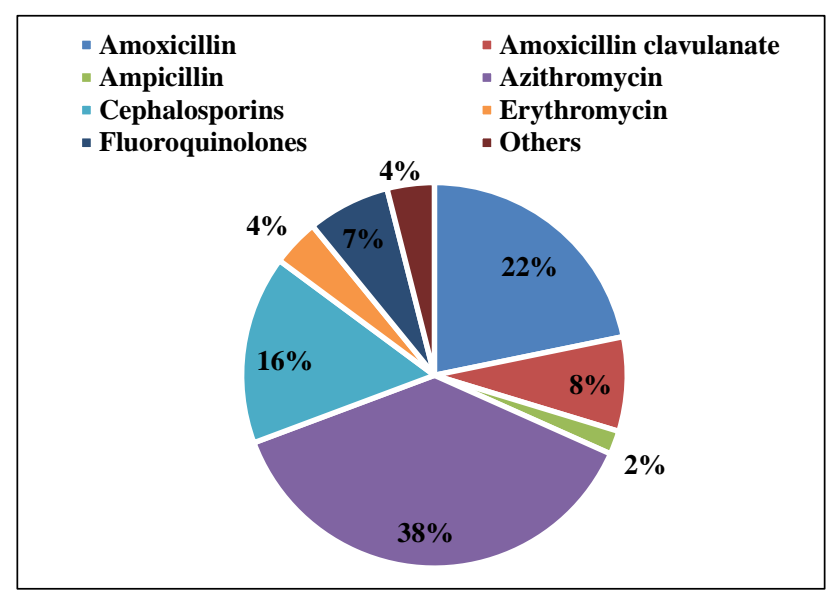

Figure 3: Distribution of the different antibiotics used by the respondents.

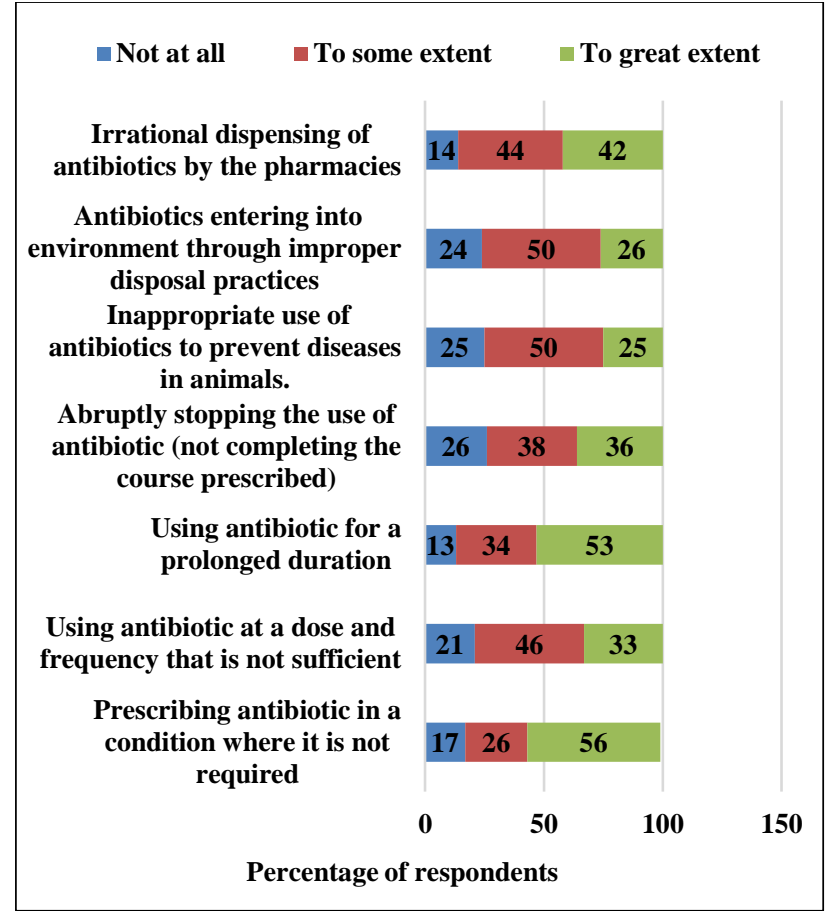

Figure 4: Respondents perception towards the extent to which contributing factors drive towards antibiotic resistance.

The method of disposal of drugs (antibiotics) followed by the respondents was evaluated (Figure 2), to which only $38 \%$ responded. Among them $47 \%$ had disposed of the drugs in the garbage and $42 \%$ saved them for future use. Only $45 \%$ of the respondents had used antibiotics in the past 3 months, and among them many had used azithromycin (38\%), followed by amoxicillin (22\%) and cephalosporins (16\%) (Figure 3).

A set of factors which may contribute to the development and spread of antibiotic resistance were mentioned in the questionnaire and the respondents were asked the extent to which the factors may contribute to the issue of antibiotic resistance. The perception of the respondents towards the above-mentioned contributing factors was evaluated (Figure 4).

\section{DISCUSSION}

In present study it was observed that many of the respondents were aware of antibiotic resistance, and its seriousness globally as well as in India. This observation is the same as in previous studies..$^{2,5,7,8}$ Many of them had a score of 5-7 for questions included under the context of knowledge, the frequency was more in students in the fourth year of MBBS (97\%), and third year (96\%), while $85 \%$ of respondents in first and second year of MBBS had scored similarly. Most of the students $(66 \%)$ had one or more persons known to them in the field of healthcare, probably the reason for better knowledge regarding antibiotic use. 
Many of the respondents had good knowledge regarding the use of antibiotics, many of them were aware that antibiotics should not be used in viral infections (83\%), antibiotics do not speed up the recovery from cold, cough $(72 \%)$ and frequent and irrational use of antibiotics can render them ineffective on future use (96\%). In comparison to the above questions, only $65 \%$ of the respondents were aware of the fact that a proper prescription is required for purchase of antibiotics at the pharmacy. On the contrary, the attitude of the respondents towards use of antibiotics was not satisfactory. Only $30 \%$ of respondents disagreed to the statements like "antibiotics should be stopped once symptoms are relieved", and 50\% agreed to the statement "Using newer antibiotics will effectively treat bacterial infections". There is a need to educate them about proper and judicious use of antibiotics.

In case of practices, only $5 \%$ of respondents exhibited a practice of self-medication. This is quite contrary to previous studies, where the self-medication behaviour was comparatively more., ${ }^{2,4}$ Many of the respondents exhibited good practices like using antibiotics only on doctor's prescription (83\%), completing the prescribed course $(74 \%)$, and only a few respondents $(8 \%)$ had actually asked the doctor to prescribe antibiotics when not prescribed. There were some respondents $(55 \%)$ who had purchased the antibiotics without a valid prescription. Educational interventions and policy making involving the pharmacies for proper drug dispensing practices is necessary. Further on evaluation of the antibiotic usage behaviour (practices), 45\%, 39\% and $31 \%$ of the respondents actually had never used antibiotics for common cold, cough and diarrhoea respectively. In case of drug disposal practices, some of the respondents (18\%) had disposed in garbage, while $16 \%$ had saved for future use. There is a requirement to sensitize them about proper drug disposal practices.

On evaluation of the perceptions of the respondents towards the contributing factors to antibiotic resistance, $50 \%$ of the respondents were of the opinion that inappropriate use in animals, and improper disposal practices contribute to some extent.

Some respondents $(56 \%)$ were of the opinion that using antibiotic when not necessary contributes to a great extent, and according to $53 \%$ of respondents use of antibiotics for a prolonged duration contributes to a great extent to antibiotic resistance. As the future prescribers, the medical students should implement rational prescribing practices in order to lessen the burden of antibiotic resistance on the society.

As stated in previous studies, problem-based learning with case scenarios can be an effective method of education in this context. ${ }^{10}$ Inclusion of program-based modules on diagnosis, prevention and control of infections and on prescribing antibiotics can be included in the curriculum.10 Due to false beliefs and notions, common public pressurize the doctor to prescribe antibiotics. Thus, development of effective communication skills in the medical students is necessary so that they communicate with the patient properly and explain to them the rational use of antibiotics.

Limitations of the present study included undergraduate medical students from all the four years, and the response rate was good. As the study population was from a single medical college, it may not represent the medical students on the whole, a large-scale study including different medical institutions could possibly help to provide a wider perspective.

\section{CONCLUSION}

In the present study, the respondents exhibited good knowledge about antibiotic use, and followed some good practices in the same context. Inspite of the good knowledge, there are some lacunae in antibiotic use behaviours in some common conditions. Thus, present study addresses the need to include certain educational strategies in the curriculum to improve or upgrade the knowledge of the medical students regarding proper and judicious use of antibiotics.

\section{ACKNOWLEDGEMENTS}

Authors would like to thank Dr. K. Santosh kumar, Professor and Head, Department of Pharmacology, KAMSRC, Hyderabad, and Dr. L. Ramesh, Professor, Department of Pharmacology, KAMSRC, Hyderabad for their valuable support and guidance.

Funding: No funding sources

Conflict of interest: None declared

Ethical approval: The study was approved by the Institutional Ethics Committee

\section{REFERENCES}

1. Ventola CL. The antibiotic resistance crisis: part 1: causes and threats. Phar Therap. 2015;40(4):277.

2. Yanhong $\mathrm{Hu}$, Wang $\mathrm{X}$. Knowledge, attitude, and practice with respect to antibiotic use among chinese medical students: A multicentre cross-sectional study. Int J Environ Res. Public Health. 2018;15(6):1165.

3. Dyar OJ, Ce'line Pulcini C. European medical students: a first multicentre study of knowledge, attitudes and perceptions of antibiotic prescribing and antibiotic resistance. $\mathrm{J}$ Antimicrob Chemother 2013;69(3):842-6.

4. Lv B, Zhou Z, Xu G, Yang D, Wu L, Shen Q, et al. Knowledge, attitudes and practices concerning selfmedication with antibiotics among university students in western China. Trop Med Int Health. 2014;19(7):769-79.

5. Mukharjee SK, Mahmud I, Akter S, Hossain S. Knowledge, attitudes and practices regarding antibiotic use among the students of microbiology department at Noakhali science and technology 
university, Bangladesh. J Drug Delive Therap. 2017;7(4):34-7.

6. Tevatia S, Chaudhry S. A questionnaire based survey on knowledge, attitude and practice of antibiotics among dental and paramedical students: a cross sectional survey. World J Phar Pharmaceu Sci. 2016;5(5):1205-6.

7. Khan A, Banu G, Reshma KK. Antibiotic resistance and usage: a survey on the knowledge, attitude, perceptions and practices among the medical students of a southern Indian Teaching Hospital. J Clin Diag Res. 2013;7(8):1613-6.

8. Padmanabha TS, Nandini T, Manu G, Madhav K. Savkar, Shankar RM. Knowledge, attitude and practices of antibiotic usage among the medical undergraduates of a tertiary care teaching hospital: an observational cross-sectional study. Int J Basic Clin Pharmacol. 2016;5(6):2432-37.

9. Zafar SN, Syed R, Waqar S, Zubairi AJ, Vaqar T, Shaikh $M$ et al. Self-medication amongst university students of Karachi: prevalence, knowledge and attitudes. J Pakistan Med Asso. 2008,58(4):214-7.

10. Lee CR, Lee JH, Kang LW, Jeong BC, Lee SH. Educational Effectiveness, Target, and Content forPrudent Antibiotic Use. Bio Res Int. 2015;8:1-13.

Cite this article as: Bhavika D, Pavani ANT, Meghavani G, Jillella A, Zaman SU. Study on knowledge, attitude and practices with respect to antibiotic use among medical students. Int J Basic Clin Pharmacol 2019;8:1628-33. 